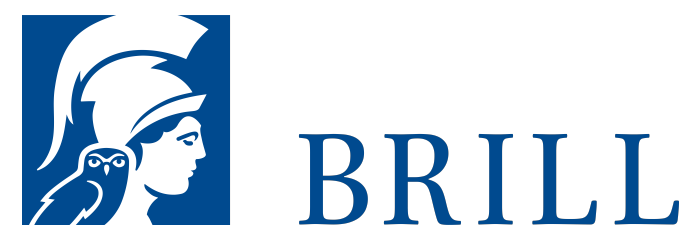

\title{
Die Form des Chaos
}

Bild und Erkenntnis in der komplexen Dynamik und der fraktalen Geometrie

Author: Nina Samuel

In den letzten Jahrzehnten haben die bildgebenden Möglichkeiten des Computers zum vieldiskutierten »Pictorial Turn « - der Wende zum Bild - in den Naturwissenschaften geführt. Mit dem öffentlichkeitswirksamen Auftritt der Bilder von Chaos und fraktaler Geometrie sowie ihrer breiten Popularisierung ab Mitte der 198oer-Jahre erfasste dieser Trend auch die Mathematik und damit diejenige Disziplin, die als »Reich des reinen Denkens « traditionell für ihre Bilderskepsis bekannt war.

Die Bilder dieses Forschungsfelds werden in der vorliegenden Studie zum ersten Mal bildtheoretisch reflektiert und diskutiert. Im Zentrum stehen Arbeitsmaterialien aus privaten Bildarchiven von Mathematikern und Physikern. Eine besondere Rolle spielt dabei die Handzeichnung als Denkform, die auf der Schwelle zum digitalen Medienumbruch eine neue Schwungkraft gewinnt.

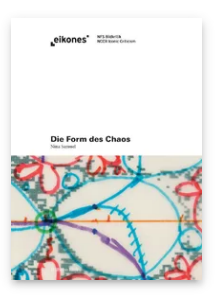

Pages: 551

Seiten, $190 \mathrm{~s} / \mathrm{w}$ und 50 farb. Abb.

Language:

German

Subjects: Art

History, Art

History

Publisher: Brill |

Fink

Series: Eikones

E-Book (PDF)

Released online:

10 Aug 2020

ISBN: 978-3-

8467-5776-5

List price

Hardback

Publication date: 20 Oct 2014

ISBN: 978-37705-5776-9

List price 
Nina Samuel ist Kunsthistorikerin und Kuratorin. Sie promovierte an der Humboldt Universität zu Berlin über "Die Form des Chaos. Bild und Erkenntnis in der komplexen Dynamik und der fraktalen Geometrie". Ihre Forschungsschwerpunkte sind: visuelle Epistemologien der Naturwissenschaften und der Mathematik, Zeichnung als Wissensprozess, Chaos und Bildtheorie, Kunst und Technik, sowie visuelle Praktiken der Biologie. Sie hatte zahlreiche Forschungspositionen inne und war Visiting Assistant Professor am Bard Graduate Center in New York City, wo sie die Ausstellung "The Islands of Benoît Mandelbrot: Fractals, Chaos, and the Materiality of Thinking" kuratierte.

For more information see brill.com

Order information: Order online at brill.com +44330 333 o049 | customerservices@brill.com Submission information: brill.com/authors

Titles published by Brill | Fink, Brill | mentis or Brill | Schöningh: +49(o)71 5413279216 | brill@brocom.de 